\title{
EFFICIENT REMEDIES FOR BREACH OF WARRANTY
}

\author{
Kenneth Chapman* and Michael J. Meurer ${ }^{*}$
}

\section{INTRODUCTION}

The warranty is a pervasive element of both commercial and consumer sales contracts; ${ }^{\prime}$ besides price and quantity terms, it is often the most important item in contract negotiation. For example, competition for sales in the automobile industry through warranty terms is particularly striking, ${ }^{2}$ and in some industrial markets, warranty cost is a major expense for firms. ${ }^{3}$ Because of the economic significance of warranties, economists have elaborated a substantial body of literature explaining their role in transactions. ${ }^{4}$ The understanding of the legal attributes of warranties manifest in these analyses is rather coarse, combining the notion of a warranty as a promise about product characteristics with the notion of a warranty as a remedy for breach of the promise. While this imprecision does not subvert the logic of the authors' arguments, it may have diverted their attention from some interesting issues associated with warranty use.

This article attempts to suggest valuable refinements and extensions of the economic theory of warranty by explicitly considering the choice of remedies

Copyright (C) 1989 by Law and Contemporary Problems

* Assistant Professor of Managerial Economics, the State University of New York, Buffalo School of Management.

$\dagger$ Assistant Professor of Economics; Lecturer in Law, Duke University.

Thanks to Isaac Ehrlich, Dan Graham, Bob Marshall, Joe Stiglitz, and Roy Weintraub for helpful comments.

1. The economics literature on warranties has primarily addressed consumer warranties. See infra articles cited in note 4 and in Part III. But warranties are common in commercial transactions as well as consumer transactions. See A. Schwartz \& R. Scott, Commercial Transactions: Principles and Policies 200-06 (1982).

2. See Cooper \& Ross, Product Warranties and Double Moral Hazard, 16 Rand J. Econ. 103 (1985); J. Lacko, Product Quality and Information in the Used Car Market (1987) (Bureau of Economics Staff Report to the Federal Trade Commission).

3. One survey of 369 industrial product warranties found that $40 \%$ of the firms sampled had warranty costs that were $2 \%$ or more of their total revenues. See E. MCGuire, Industrial Product Warranties (1980). For products described as scientific equipment and controls, $24 \%$ of the sampled firms had warranty costs that were $5 \%$ or more of total revenues. See id. A survey of the used car market found that warranties add $10 \%$ to the price of a car. See J. LACko, supra note 2, at 64 .

4. See infra Part III for a discussion of this literature. Warranties are viewed as a risk-sharing device in Heal, Guarantees and Risk Sharing, 44 REv. Econ. Stud. 549 (1977). Articles modeling warranties as devices for quality disclosure include: Courville \& Hausman, Warranty Scope and Reliability under Imperfect Information and Alternative Market Structures, 92 J. Bus. 361 (1979); Grossman, The Information Role of Warranties and Private Disclosure about Product Quality, 24 J. L. \& Econ. 461 (1981); Spence, Consumer Misperceptions, Product Failure and Product Liability, 44 Rev. Econ. STUD. 561 (1977). Warranties as a means of quality control are discussed in Cooper \& Ross, supra note 2. 
for breach of warranty in conjunction with the choice of warranty protection itself. In particular, it offers explanations for the prevalence of replacement terms rather than refund terms in warranties. Economists studying the general issue of breach of contract have noted that the choice of remedy has important implications for risk sharing, renegotiation, transaction-specific investment, and the incentive to breach. ${ }^{5}$ This article derives much of its insight from the recognition that work on the economics of contract breach has much to say that is relevant to the economics of warranties.

Part II of the article describes the remedies explicitly provided for breach of warranty in commercial and consumer contracts, as well as the remedies provided by the Uniform Commercial Code ("UCC") that may be applicable when the contract is silent on the issue. This section probes beyond the formal statement of remedies to explore the law and economics of warranty disputes. Even though settlement negotiations may lead to the selection of a remedy not listed in the contract or called for by law, the contract remedies and UCC do affect the outcome of negotiation.

The third part of the article reviews economic theories concerning the purpose of warranties. It argues that these theories offer an incomplete understanding of warranties since they fail to explain adequately the selection of remedy terms in warranties. Parts IV.A through IV.C develop new economic theories explaining the purpose of warranties and the observed pattern of remedy selection in warranty policies.

II

\section{Warranty Law and Related Topics in Contract LaW}

We begin this section by describing warranty terms that commonly are included in contracts. The parties to many contracts, however, fail to specify their preferences for remedies for breach of warranty, as well as other warranty terms. Presumably, the parties in such cases intend to rely on the default terms provided by contract law. Thus, the warranty terms offered by the UCC to govern sales contracts are also recounted.

Most of the survey work on warranties has been impressionistic rather than systematic. ${ }^{6}$ Scholars studying the warranty terms in observed contracts, however, are in consensus regarding certain features of warranties. Examination of contracts reveals that in both consumer and commercial agreements the warranty clauses almost always call for repair or replacement of defective parts or products. ${ }^{7}$ Furthermore, consumer contracts generally

5. See generally Readings in the Economics of Contract Law (V. Goldberg ed. 1989).

6. See, e.g., Priest, $A$ Theory of the Consumer Product Warranty, 90 YALE L.J. 1297 (1981); Schwartz \& Wilde, Imperfect Information in Markets for Contract Terms: The Examples of Warranties and Security Interests, 69 VA. L. REv. 1387 (1983).

7. A careful survey of service managers at firms manufacturing industrial products revealed that $87.2 \%$ of warranties provided for replacement of defective parts and $70.8 \%$ covered the expense of repair. D. Berry, Warranty and Service Costs Study 4 (1985) (unpublished manuscript). See also H. Greenberg, Rights and Remedies under U.C.C. Article 2, at 319 (1987); Priest, supra note 6, at 1319-27; Schwartz \& Wilde, supra note 6, at 1416. These studies are incomplete in that they only 
exclude consequential damages. ${ }^{8}$ Money-refund warranties are normally found only in two contexts, either coupled with satisfaction guarantees, or offered by retailers. ${ }^{9}$

On first thought the prevalence of repair-or-replacement warranties is surprising to economists because consumers should prefer money-refund warranties. Refunds are a type of cash transfer from the seller to the buyer, while repair and replacement constitute in-kind transfers. Economists are quick to argue that cash transfers are more efficient than in-kind transfers. ${ }^{10}$ For example, with regard to welfare benefits, a cash payment is more efficient than food stamp benefits because it gives the recipient greater freedom of choice. Cash can be used to purchase anything; food stamps can only be exchanged for food.

Likewise, a consumer experiencing breach of warranty could take a money refund and repurchase the original product if he so desired, achieving the same result as repair-or-replacement remedies. Furthermore, the consumer would have the freedom to switch to some other product. In a competitive market, firms must offer efficient contract terms to survive. Even in a monopoly market the seller would offer the efficient warranty to consumers to maximize the value of the transaction. It then extracts greater profit through higher prices than would be possible given an inefficient warranty.

Regardless of market structure, if the cost of the different remedies is the same to the seller, then the seller has an incentive to provide the type of warranty desired by the consumer. Thus, money-refund warranties should predominate. To counter this argument one can claim either that the cost of repair-or-replacement warranties is lower than the cost of a money refund, or that there are subtle advantages to either buyers or sellers from these remedies that offset the obvious advantage of the money-refund warranty. This article does not consider the relative costs of the different warranty remedies. Rather, it explains the prevalence of repair and replacement terms by arguing that they are superior to refund. Part III considers the advantage of a repair remedy as compared to a refund. Parts IV.A through IV.C suggest advantages of replacement warranties.

Beyond explaining the prevalence of repair-or-replacement warranties, this article addresses the normative question of the appropriate content of

analyze standard warranty policies. If a warranty is granted implicitly, then the remedy most probably will be damages. Also, since express oral warranties are usually not accompanied with a specification of remedies, the probable remedy for breach of such warranties will again be damages. We have no data on how common or significant these practices are.

8. See Priest, supra note 6, at 1301-02. The effect of such exclusion, however, is questionable since many courts bar limitations on consequential damages in consumer contracts. See D. WHALEY, Warranties and the Practitioner 118 (1981).

9. This judgment is based on the surveys cited in note 7 (showing that refunds are uncommon in manufacturers' contracts for either consumer or industrial goods) and the authors' informal survey of consumer warranty policies.

10. See, e.g., H. Rosen, Public Finance 164-65 (1988) (in-kind food transfers to the poor are less efficient than cash transfers). 
contract law concerning warranties. ${ }^{\prime}$ The normative criterion invoked by economists is efficiency. Contract law can affect the efficiency of sales agreements directly by proscribing or commanding certain contract terms, and indirectly by providing a backdrop against which contract negotiations proceed. If the negotiators fail to provide for a contingency in their contract, then contract law fills the gap. Specifically, if the contract is silent on whether repair, replacement, or refund is an appropriate remedy for breach of warranty, contract law should impose the optimal remedy.

Before delving into the discussion of the questions outlined above, it is worthwhile to develop a brief primer of warranty law. ${ }^{12} \mathrm{~A}$ warranty is a representation by the seller of a characteristic of the product offered for sale. The representation is factual rather than mere puffing, and generally pertains to either a matter of reliability or suitability of a product. The representation may be either express or implied; in the latter case reliability is promised in the implied warranty of merchantability, and suitability is promised in the implied warranty of fitness for a particular purpose. Implied warranties may be waived and a product sold as is. Often a warranty is a promise that a machine will operate as intended, but a warranty may also be a promise that a product has a certain composition-for example, that the fat content of meat is below some level. ${ }^{13}$ In addition, a warranty might promise that a durable product, such as house paint, will last for a certain number of years.

A warranty then is a promise, and if that promise is breached, some remedy must be forthcoming. The remedy may be provided for explicitly in a contract, calling for the repair or replacement of the product in question, or for the refund of some portion of the sales price to the buyer. Additionally, the warranty clause may limit or exclude certain types of damage claims. ${ }^{14}$ Finally, a schedule of liquidated damages may be specified.

Often the remedy for breach of an express warranty is not specified in the sales contract, and of course, the remedy for breach of an implied warranty is not specified by the parties. In a contract covered by the UCC, ${ }^{15}$ sections 2 601 through 2-609, supply contractual terms applicable when nonconforming goods are delivered and the contract is silent on the matter. The UCC's approach codifies the common law doctrine known as the "perfect tender" rule. The buyer may reject delivery "if the goods ... fail in any

11. See infra Part IV.B for a discussion of the efficiency of expectation damages and replacement remedies.

12. The material contained in this and the following paragraph can be found in H. GREEnBERG, supra note 7 .

13. See J.D. Pavlak, Ltd. v. William Davies Co., Inc., 40 Ill. App. 3d 1, 351 N.E.2d 243 (1976).

14. Many warranty policies exclude consequential damages. See D. WhaleY, supra note 8, at 115. Contract clauses exonerating the seller for consequential damages resulting from physical injuries to the buyer are not allowed. Id. at 111 . In addition to recovery under contract theory, product liability law offers compensation in the event of physical injury. This article will not address issues involving physical injury.

15. Article 2 of the UCC is very broad, governing all "transactions in goods." UCC § 2-102 (1977). It has been adopted by every state except Louisiana, as well as the District of Columbia, the Virgin Islands, and Guam. Unif. Commercial Code, 1 U.L.A. 1-2 (Supp. 1989) (table of jurisdictions in which Code has been adopted). 
respect to conform to the contract ...."16 If a buyer accepts delivery and later discovers the non-conformity, he or she may revoke acceptance if there is a substantial impairment of value to the buyer. ${ }^{17}$ The buyer may also accept the goods and seek damages. ${ }^{18}$

The right of the buyer to reject delivery is coupled with the right of the seller to cure a non-conformity after rejection, meaning that the seller may repair or replace the non-conforming goods. ${ }^{19}$ However, the right to cure does not follow revocation, the Code is silent on this matter, and the "majority rule is that the seller has no statutory right to cure . .."20 Thus, the UCC provides for repair, replacement, or damages at the option of the seller in the case of rejection, and after revocation the buyer may permit repair or replacement, but can demand damages if desired.

If the buyer either rejects delivery or justifiably revokes acceptance of nonconforming goods, then damages under the UCC usually include a refund of the purchase price, the cost of "cover," and consequential and incidental damages. ${ }^{21}$ If the buyer has accepted the goods and the time to revoke such acceptance has passed, then damages may be calculated "in any manner which is reasonable." 22 Under the UCC, damage awards to compensate for breach of warranty are usually measured by the difference in the value of the goods as warranted and the value of the goods received. ${ }^{23}$ In addition, a court may award incidental and consequential damages. ${ }^{24}$

Two final comments on the law of remedies for breach of warranty are relevant to the following analysis. First, specific performance is generally not available to force replacement or repair of a non-conforming good. ${ }^{25}$ As a result, a seller cannot make a credible commitment to provide repair or replacement. There may be situations following breach of warranty in which the seller would rather not provide repair or replacement, and therefore breaches this duty knowing that damages will be payable, or an out of court settlement will be reached. Furthermore, in the absence of specific performance, buyers cannot be given a meaningful election of remedy options, since the seller can always ignore the buyer's demand for repair or replacement and pay damages.

16. U.C.C. $\$ 2-601$ (1977).

17. Id. § 2-608.

18. See D. WhaLEY, supra note 8 , at 163.

19. U.C.C. $\S 2-508$ (1977).

20. H. GREENBERG, supra note 7.

21. U.C.C. \$ 2-711 (1977). Consequential damages are losses that would not have occurred in the absence of breach, and include personal injury costs, lost resale profits, lost good will, lost time on other projects, and many other types of losses. Incidental damages are costs that are incurred by the buyer in detecting and attempting to avoid breach. The significance of the distinction is that incidental damages are always recoverable, whereas consequential damages are only recoverable to the extent that they are foreseeable. See H. GreenBerg, supra note 7, at 358-61.

22. U.C.C. \& 2-714(1) (1977).

23. Id. § 2-714(2).

24. Id. \& 2-7 I4(3).

25. See H. GreENBerg, supra note 7 , at 341 . 
The other relevant area of remedy law is liquidated damages, which operates to take the decision concerning the amount of damages out of the hands of the court, making it a subject negotiated by the parties to a contract. Sufficiently high liquidated damages have the same effect as specific performance. A contract can make the commitment to provide repair or replacement credible by including a substantial disincentive for the seller to fail to honor the repair-or-replace remedy. The value of this policy is severely restricted, however, because liquidated damages are only enforceable if other remedies are inconvenient, the amount of loss is difficult to prove, and the amount of award is reasonable either ex ante or ex post. ${ }^{26}$

Given the state of the law, two remedy configurations are feasible: first, repair, replacement, or refund at the option of the seller; and second, an exclusive damage remedy. ${ }^{27}$ To understand the validity of this claim, an exhaustive set of possible remedies must be considered. An implied warranty or an express warranty with no remedy provision requires reference to the common law or a state's incarnation of the UCC for the applicable remedy. As noted above, the UCC provides that after rejection of non-conforming goods the seller has the option to cure the non-conformity. ${ }^{28}$ In other words, the Code provides the seller with the choice of repair, replacement, or damages.

Next, consider the cases arising when remedies are explicitly specified in the contract. If a contract calls for refund, then the parties could bargain for repair or replacement instead, but neither party could insist upon it. ${ }^{29}$ An explicit repair-or-replace provision can be ignored by the seller, effectively giving the seller the option to choose money damages or to attempt to make an out of court settlement payment. In contrast, a contract giving the seller the choice of all three remedies achieves its intended effect. Finally, if a contract gives the buyer the option to choose the remedy type, the effect is the same as agreeing to an exclusive money-refund remedy, since either party could refuse repair or replacement.

Although the law does not make credible either an exclusive repair-orreplace remedy or an agreement to give the buyer the remedy choice,

26. Id. at 252-53.

27. It should be emphasized that consequential damages may be recoverable after replacement has occurred, creating a coupling of replacement and damage payments other than refund of the purchase price. See H. GREENBERG, supra note 7, at 357. Additionally, contracts can limit consequential damages by exclusion or by liquidated damages provisions. See id. at 248-49, 252 .

28. Attention is placed on rejection rather than revocation of acceptance because revocation is possible only when the value to the buyer is substantially impaired and either discovery of nonconformity was difficult at the time of acceptance or the buyer reasonably assumed the nonconformity would be cured. U.C.C. $\$ 2-608$ (1977). The requirements for revocation are more stringent than for rejection, and the buyer is in a stronger legal position following rejection should the dispute go to trial. See D. Whaley, supra note 8, at 176-77. The only practicable remedy after revocation is damages. See H. GreEnberg, supra note 7, at 319 .

29. The same situation prevails under the UCC after revocation of acceptance. See H. GreEnBerg, supra note 7 , at 341 . 
economic forces may accomplish this end. ${ }^{30}$ Note that the seller incurs various costs by ignoring the contractual remedies. Settlement and potential litigation costs are obvious costs that can be avoided by honoring a replacement promise. The seller also avoids the uncertainty of litigation and settlement negotiations. Furthermore, the seller suffers loss of reputation by breaching the warranty. In addition, the seller might hesitate to contravene the remedy terms in the warranty out of fear of liability for consequential damages. When consequential damages have been excluded by the contract, the seller might become liable for them because refusal to honor the repairor-replacement agreement may void the exclusion. ${ }^{31}$

Two of these economic factors impact more substantially in consumer goods markets than in commercial transactions. ${ }^{32}$ In consumer markets a reputation for fair customer complaint management is an important determinant of brand loyalty. ${ }^{33}$ In contrast, buyers in the commercial sector are likely to be better informed about suppliers, diminishing the role of reputation. Furthermore, possible exposure to consequential damages is a more potent deterrent to refusal to repair or replace in consumer markets because of the widespread use of limitations on consequential damages in consumer contracts.

Before proceeding to an economic analysis of remedies for breach of warranty, it is time to take stock of the feasible remedy configurations. The UCC stipulates that the remedy is selected at the seller's option following rejection of non-conforming goods. The four variations of contractual remedies are as follows: exclusive repair or replacement, exclusive refund, seller's option, and buyer's option. Given certain conditions, the possibility of seller's breach of repair-or-replace clauses reduces the possible choices to either exclusive refund or seller's option.

This taxonomy is helpful in interpreting warranty terms in contracts observed in the economy. The refund remedy is rarely observed in

30. The absence of any sources noting that firms frequently refuse to honor the replacement provisions of warranty agreements provides strong evidence that in the consumer context, some force works to ensure that firms provide replacements instead of paying damages.

31. See H. GREenberg, supra note 7, at 246-50. If repair or replacement is the exclusive contract remedy and the seller will not perform, then under the UCC the remedy fails its essential purpose, and the buyer may turn to other remedies provided by the UCC. U.C.C. $\$ 2-719$ (1977). See Carboline Co. v. Oxmoor Center, 40 U.C.C. Rep. Serv. 1728 (Callaghan) (Ky. Ct. App. 1985); Mostek Corp. v. Chemetron Corp., 40 U.C.C. Rep. Serv. 840 (Callaghan) (Ill. Ct. App. 1982). See generally Kanovitz, Warranties with Exclusive Repair-and-Replace Remedies: When Does the Buyer's Cause of Action Accrue?, 1984 ARIz. ST. L.J. 431. Courts are divided on whether the consequential damages provision is severable. See H. Greenberg, supra note 7, at 249. This potential cost of refusing to replace is less important in jurisdictions in which exclusion of consequential damages in consumer contracts is disallowed.

32. For products such as small appliances that are covered by both the manufacturer's repair-orreplace warranty and the retailer's money-refund warranty, the buyer is given an option of remedy choice.

33. See C. Fornell \& B. Wernerfelt, A Model for Customer Complaint Management: A Segmentation Approach 11 (Aug. 1986) (unpublished manuscript) (arguing that the "introduction of complaint management could increase market share [in the eye glass industry] by about 10 percentage points"). 
combination with a warranty of merchantability. ${ }^{34}$ The repair-or-replace remedy that accompanies such warranties is likely to be credible in consumer goods markets, but may be better viewed as creating an option for the seller to choose either repair, replacement, or refund in commercial transactions. In commercial contracts governed by the UCC that are silent on the remedy, the seller also has the option of remedy choices. Given the economic presumption in favor of the refund remedy, we turn now to the existing economic explanations of warranties to look for some insight into the question of remedy choice. ${ }^{35}$

\section{ECONOMIC ThEORIES OF WARRANTY}

Perhaps the most obvious explanation for the existence of warranties is that they provide insurance against product failure or dissatisfaction to riskaverse consumers. ${ }^{36}$ The insurance is usually bundled with the product rather than sold separately by an insurance company for several reasons. ${ }^{37}$ The manufacturer may find it easier to detect product misuse by a consumer than a third party would, alleviating consumer moral hazard. ${ }^{38}$ Manufacturers might bundle the insurance and the product in order to achieve price discrimination, ${ }^{39}$ or the transaction costs of seeking out a separate insurer might be so large as to make third-party insurance infeasible.

The insurance theory offers little hope of explaining the preference for repair-or-replace warranties. Usually, repair-or-replace warranties and refund warranties provide equally effective insurance, although both have their faults. One difficulty with the repair-or-replace remedy occurs when the vendor is incapable of providing a satisfactory product. ${ }^{40}$ This might happen in the case

34. This judgment is based on the authors' informal survey of warranty terms in contracts. See also infra note 52 (discussing the "party dress" moral hazard problem that results from the combining of these two warranty provisions).

35. Refund provisions accompanying satisfaction guarantees are credible. There is no economic mystery surrounding the choice of the refund remedy for this type of transaction. That is, if a product is unsuitable because it does not satisfy a particular consumer's needs or tastes, then a repair-or-replacement remedy is of no value. This type of warranty is excluded from the subsequent discussion.

36. The question of whether firms are risk-averse or risk-neutral is disputed, so this discussion will focus on consumers.

37. Insurance against product failure is not always bundled with the product. Sellers as well as third parties commonly offer separate service contracts, especially when selling cars and appliances.

38. "Moral hazard arises when an agent can influence the occurrence of an event (here product failure) against which the agent is insured, but the seller of the insurance policy cannot monitor or detect this action. In the case of warranty, the terms of the warranty may create an incentive for the buyer to give his [product] insufficient maintenance ..." or use it carelessly. L. PhILIPS, The ECONOMICS OF IMPERFECT INFORMATION 58 (1988).

39. See Braverman, Gausch \& Salop, Defects in Disneyland: Quality Control as a Two-Part Tariff, 50 Rev. Econ. Stud. 121 (1983); Kubo, Quality Uncertainty and Guarantee, 30 Eur. Econ. Rev. 1063 (1986).

40. A problem may also arise when the buyer seeks to insure against the risk that the product will not be suitable for his or her purpose. For certain products known as "experience goods," the buyer can judge suitability only after use. Thus, a consumer may discover after purchase that he or 
of a new product or new design that is inherently unmerchantable, so that a working product cannot be produced at reasonable cost. ${ }^{41}$

With a money refund, the buyer can purchase another unit of the product and be in the same position as he would have been following repair or replacement. However, the refund fails to provide the same insurance as the repair-or-replace remedy if a repurchaser faces a higher price than the original purchase price. The higher price could result either from price discrimination against the repurchaser or from a general price increase for the product. ${ }^{42}$ Price discrimination is simply the practice of charging different prices to different types of customers. It is not likely to succeed in mass markets for consumer goods because of the difficulty in identifying particular consumers as repurchasers. Price discrimination in commercial markets is more plausible. ${ }^{43}$ The problem created by a general price increase could be avoided by making the refund equal to the larger of either the current market value or the original sales price. ${ }^{44}$

The insurance theory of warranties may be valid, but it is incomplete, since it fails to explain the paucity of refund remedies. The theory is also limited by the fact that consumer warranties are incomplete in their coverage and limited in duration compared to product life, thereby providing incomplete insurance. These failings lead economists to search for additional or alternative explanations for warranties.

A second candidate is the comparative advantage theory, which contends that warranties optimally assign the responsibility for quality control, maintenance, and repair to buyers and sellers. Priest ${ }^{45}$ suggests the example of refrigerators in which warranties cover the motor, but not the door. Presumably, the motor fails because of problems at the factory rather than anything the consumer does. On the other hand, consumer misuse could damage the door, and lack of warranty coverage for that item would encourage the consumer to take care.

This theory is useful in explaining the predilection toward repair instead of refund remedies. A seller may have a comparative advantage in repair of a product as compared to a repairperson hired by the buyer, because of a cheaper inventory of repair parts, greater knowledge of the technology, or

she cannot be well matched with any of a seller's products. A repair-or-replacement warranty fails to provide valuable insurance in this case.

41. In such a case, the courts interpreting the UCC probably would find that the remedy clause fails its essential purpose and would award money damages. See supra note 28.

42. Discrimination in a mass consumer market is also difficult because of the ease of arbitrage through resale. Furthermore, the would-be victim of discrimination could find an agent who does not fall into the disfavored category to make the purchase.

43. Discussion of this topic is deferred to Part IV.A. Although price discrimination may be possible in commercial markets, commercial buyers may not have a sufficient interest in the insurance properties of a warranty. Economists often argue that firms should act as if they are riskneutral. Even if they are not, there is no reason to believe that the buyer is more risk-averse than the seller and will seek insurance through a warranty agreement.

44. This tactic may create a consumer moral hazard problem whereby the consumer deliberately breaks the product to capture the value of the price increase.

45. Priest, supra note 6, at 1309. 
information gained by the manufacturer's product designers and engineers from repair experience. In this case a payment covering the cost of repair is inefficient compared to repair as a remedy. However, if repair is not feasible, then replacement and refund warranties should be equally effective in maintaining the appropriate level of quality control by the seller, while care is induced from the buyer by the limitations of the warranty.

While the comparative advantage theory explains the prevalence of repair warranties, it does not explain the preference for replacement warranties over refund warranties. To analyze this issue, consider a third theory for the existence of warranties, which emphasizes the potential asymmetry of product quality information between the buyer and the seller. Imagine a market in which product quality (measured by failure rate) varies across firms. High quality goods are sold by some firms, while others sell low quality goods. Whether a firm has a high or low quality product is exogenously determined. Consumers can only determine product quality through use. ${ }^{46}$ At the time of purchase the products are indistinguishable.

The ability of low quality firms to charge the same price as high quality firms for an inferior product works to the disadvantage of consumers and high quality firms. To distinguish themselves, high quality firms offer longer warranties. The longer warranty is a signal to consumers regarding the high quality of a seller's product. ${ }^{47}$

The low quality firms would be tempted to match the warranty policy of high quality firms to convince consumers that they too are high quality, but a given warranty would be more costly for a low quality firm because of more frequent failures. If the cost difference is sufficiently large, the low quality firm will not imitate the high quality firm. High quality firms will be able to charge a higher price to cover the greater warranty expenses and cost of making a high quality product.

This theory does not fare well when confronted with data showing that warranty coverage is quite uniform within industries, even though product quality is variable. ${ }^{48}$ Furthermore, for the theory to establish a distinction between replacement and refund warranties, it must be true that the warranty cost difference between high and low quality firms is more pronounced for one of the remedies. It is not clear why the warranty costs under the two remedies might differ. ${ }^{49}$

46. This proposition assumes that direct inspection by consumers, word of mouth, and reports from sources such as newspapers or consumer reports are insufficient to fully inform buyers about quality.

47. For a more sophisticated discussion of the signaling role of warranties, see Grossman, supra note 4; Spence, supra note 4; K. Chapman, Can Warranties Signal Quality: Constraining Warranty to be Less than Price (June 1988) (unpublished manuscript).

48. See Priest, supra note 6, at 1319-46; Gavin, Quality on the Line, Harv. Bus. Rev., Sept.-Oct. 1983 , at 65 .

49. If the buyer receiving the money refund repurchases the original product, then the cost of refund warranties is the same as the cost of replacement warranties since in both cases, the seller incurs the cost of providing one more unit. If the buyer leaves the market or purchases the product from another seller, however, then the difference in the warranty costs of high and low quality firms 
Besides the signaling model, the asymmetry of product quality information gives rise to a model of warranties based on the moral hazard facing the seller. ${ }^{50}$ In this model, firms are identical and can control quality by exerting effort. In the absence of warranties an inefficiently low level of quality is provided. This result follows because consumers cannot determine quality before purchase, and firms reduce production costs by skimping on quality control.51 By moving the risk of failure from the buyer to the seller, full warranty induces the efficient level of quality control by the firm. As in the comparative advantage model, however, the necessary incentives can be provided using either replacement or refund as the remedy. ${ }^{52}$

The final possible role of warranties described in the economics literature is as a tool of price discrimination. ${ }^{53}$ Models in this vein assume that heterogeneous customers face a monopolist who sets price, quality, and warranty terms. ${ }^{54}$ The warranty is used to sort customers according to their degree of risk aversion. A schedule of prices, quality levels, and warranty terms is offered to customers, and discrimination is achieved as they sort themselves. The high valuation customers choose the most complete warranty coverage, pay the highest price, and get the highest quality. ${ }^{55}$ In these models little attention has been paid to the nature of the remedy, since the product is provided by a monopolist. Consumers experiencing failure repurchase the monopolist's product, making refunds equivalent to replacements. ${ }^{56}$

is greater for the refund warranty. Specifically, the difference in refund warranty costs between high and low quality firms is $\left(f_{L}-f_{H}\right) P$, where $f$ is the probability of product failure, $P$ is the price of the product, and $H$ and $L$ represent high and low quality. With a replacement warranty, the cost difference is $f_{L} C_{L}-f_{H} C_{H}$, where $C$ is the marginal cost of producing an additional unit. Since the cost of a product is generally less than the price of a product, the cost difference for refund warranties will generally be greater than the cost difference of replacement warranties. This difference is further compounded by the fact that $C_{l}$ is usually less than $C_{H}$.

50. See Cooper \& Ross, supra note 2.

51. Firms' concern for their reputations will alleviate but not eliminate this problem.

52. Buyer moral hazard may shed some light on the different roles for replacement and refund remedies. There are two circumstances under which a buyer facing a refund remedy has an incentive to cause product failure. First, there is the "party dress" moral hazard problem whereby a consumer can get an essentially free rental of an item, such as a party gown, by returning it on the morning after the social event, claiming it does not fit, and receiving a refund. This danger is eliminated by a replacement remedy. Second, a buyer may also be tempted to cause product failure and seek a refund of the original purchase price when the product's price is declining. Once again, a replacement policy avoids this danger.

53. Price discrimination and warranties are discussed in Matthews \& Moore, Monopoly Provision of Quality and Warranties: An Exploration in the Theory of Multidimensional Screening, 55 ECONOMETRICA 441 (1987); Braverman, Gausch \& Salop, supra note 39.

54. Heterogeneity of customers is not necessary, as shown by Braverman, Gausch \& Salop, supra note 39. These authors present a model in which warranties are used to implement a two-part tariff that extracts consumer surplus from homogeneous consumers when demand curves are sloping down.

55. See Matthews \& Moore, supra note 53.

56. At the symposium of this issue, Bob Marshall suggested a different type of price discrimination that relies on the replacement remedy. Consider the case of the new car market. Car dealers and manufacturers may want buyers experiencing product failure to get a replacement because they can earn supernormal profits on replacement parts in the post-warranty lifetime of the car. Evidence that excessive profits are earned on replacement parts for cars is provided by Crandall, 


\section{An Economic Theory of WarRanties Distinguishing RePair AND REPLACEMENT REMEDIES}

The purpose of the preceding argument was to establish that standard form contracts containing warranties rely primarily on repair-or-replacement remedies, though the operation of contract law effectively may make these warranties enforceable by providing for damages if the seller so chooses. However, economic incentives, especially in consumer markets, may make the limitation to repair or replace credible. The review of the economic literature concerning warranties locates an explanation for a preference for repair over refund remedies, but provides no indication why replacement might be preferred to refund. This section will develop new economic theories explaining the existence of warranties that allow for a different role for replacement as compared to refund warranties.

\section{A. Replacement Warranties as a Method of Discriminating Among Customers}

It was mentioned above that economic theorists have shown that warranty policy may be implemented in such a way as to promote price and quality discrimination. Three conditions must be satisfied to enable a firm to discriminate successfully. First, a firm must gain privately held information about consumer preferences. Second, it also must implement a discriminatory marketing plan that blocks arbitrage. Arbitrage consists of excessive purchases by favored consumers, who then resell to disfavored consumers. Finally, the would-be discriminator must possess market power, or else its rivals will serve the disfavored consumers, undermining the scheme.

The models described in Part III rely on a set of screening contracts to obtain information and prevent arbitrage, where screening is achieved through a schedule of offers to sell a good in which various combinations of quality, price, and warranty coverage are proposed. ${ }^{57}$ Consumers reveal information about their private preferences through their choice of a particular contract. Arbitrage opportunities are absent because all consumers have access to the same set of offers.

A different method of achieving discrimination can be implemented using replacement warranties. Suppose that consumers differ in terms of their ability to use a product, or the suitability of the product for their needs. To simplify, suppose that there are good and bad consumers, and that good consumers experience a lower rate of failure with a particular product, or are more likely to find a product to be highly valuable than bad consumers. In this environment, a warranty claim can be used to provide information on the

Vertical Integration and the Market for Repair Parts in the U.S. Automobile Industry, 16 J. INDUs. Econ. 212 (1968).

57. Often, economists imprecisely refer to each offer as a contract whether it is accepted or not. 
consumer type; a consumer experiencing failure is more likely to be a bad type. Since the warranty claim provides the information, the distinction between remedies is not important unless one of them is more effective in preventing arbitrage. This is where replacement warranties are potentially superior to refunds.

Consider the case of a monopolist who wishes to discriminate in favor of bad types by giving them a more reliable (and more costly) product. Such discrimination might be profitable if it is efficient to provide a higher quality product to bad consumers than to good consumers. This would be the case if the increased cost of making the higher quality product was more than offset by the reduction in the failure rate for the bad type of consumers, but not for the good type.

An example will be helpful to clarify these assumptions. Suppose that the high quality product never fails and costs $C_{h}$. The low quality product has a failure rate of $f_{g}$ for good consumers and $f_{b}$ for bad consumers, where $f_{g}<f_{b}$. The low quality product costs $C_{1}$ which is less than $C_{h}$. Efficiency dictates providing the low-quality product to the good consumers if $C_{1} /\left(1-f_{g}\right)<C_{h}$, while $C_{1} /\left(1-f_{h}\right)>C_{h}$ implies that providing a high quality product to bad consumers is efficient.

Such discrimination could be achieved in a limited way by guaranteeing that after product failure, the replacement provided the consumer is of higher quality than the original product. ${ }^{58}$ The consumer receiving the replacement might be a good type consumer, but the probability that the consumer is a bad type is higher than in the population at large. A money refund does not provide this opportunity to discriminate because there is no way for the seller to distinguish new purchasers from those who have experienced failure. ${ }^{59}$

A potential problem that arises when consumers experiencing failure are treated more favorably than those not making a warranty claim is consumer moral hazard. If consumer misuse resulting in failure is not verifiable by the courts, then consumers will break their product to get the higher quality replacement. Compounding this problem is the fact that litigation is likely to

58. Quality discrimination could also be achieved if the product were leased. The lessor initially would provide low quality products to all lessees and subsequently would replace them with higher quality products after product failure.

In the hypothetical cases discussed below, it is reasonable to assume that consumers do not know their type until after they use the product. Given this assumption, the screening contracts cannot effectively discriminate among initial purchasers because the consumers are not aware of their type.

59. It is possible, however, to achieve discrimination with a money refund by giving a consumer making a warranty claim a certificate that entitles the bearer to purchase a higher quality replacement from the original seller at no additional cost. Two factors make this scheme relatively unattractive. First, arbitrage would be less costly, since it is easier to sell a certificate to a good type buyer than it is to resell a high quality product obtained as a replacement. Therefore, the transaction costs of arbitrage may be lower with a replacement warranty for the consumer wanting to exit the market and spend the refund money elsewhere. Second and more important, the refund and certificate scheme would be administratively difficult for manufacturers offering warranties on products sold through retailers. Each retailer would have to maintain a special inventory of high quality products that would only be sold to bearers of the certificate, whereas the manufacturer would maintain a single replacement inventory. 
be quite costly relative to the cost of honoring a false warranty claim for many consumer products, limiting the seller's ability to alleviate the moral hazard problem even when misuse is verifiable.

Mindful of this caveat concerning moral hazard, the appeal of this theory is greatest in application to consumer transactions in which there is little or no temptation for the consumer to cheat. If the successful operation of a product for some initial period implies that product failure is unlikely to occur prematurely, then there is no incentive to switch to the higher quality product. Furthermore, since discrimination can only occur after failure, a high failure rate is necessary to create a substantial advantage for replacement warranties.

To illustrate these points, suppose that microwave ovens will either fail in the first month of use, or else last for ten years, and that the probability of failure is lower for consumers with modern electric wiring in their homes. Further, suppose that a more expensive oven can be designed that will not fail. After the initial month of use, no consumer has an incentive to make a false claim, because the oven is known to be well made. Consumers who experience failure during that month receive the higher quality ovens.

Discrimination is achieved by providing consumers experiencing failure with a higher quality product. Why not offer both the high and low quality products for sale initially? It is likely that consumers will not know anything more about their type than the seller, and would not be able to sort themselves into one class buying the low quality good, and a second class buying the high quality good. Even if they did know their type, it might not be possible to find a profit-maximizing set of offers that would induce the bad type, but not the good type, to choose high quality.

In commercial transactions it is likely that the problem with moral hazard can be mitigated by threat of litigation, but the difference between refund and replacement warranties in achieving discrimination is less striking. As an example consider the case of photocopy machines. Imagine that certain users have a workplace that is very dusty, causing more frequent breakdown of the machine. Suppose the warranty policy called for replacement after a certain amount of down-time for a machine, and that the replacement is higher quality. This policy achieves discrimination in terms of product quality.

Discrimination could also be achieved with a refund warranty, if the refund is accompanied by a promise that the customer can purchase a new machine of higher quality. In commercial markets as contrasted to consumer markets, it would be more difficult for buyers experiencing product failure to engage in arbitrage. If the sales representative has personal knowledge of the operation of the buyer's business, he or she would be able to identify customers making purchases for resale. ${ }^{60}$

60. The discussion of warranties as a means of achieving discrimination can be extended to cover the insurance aspect of a warranty as well as the selection of product quality. If consumers learn about their type through experience with the product, then an adverse selection insurance problem is created. In a money-refund scheme, there are buyers who have no product experience, and others who have experienced failure. The latter have a higher probability of being a bad type. 


\section{B. Replacement Warranties and Cost-Reducing Investment by the Seller}

A money refund is advantageous primarily because it gives buyers the freedom to switch from one product to another. A major disadvantage is that buyers may be forced to switch to another product. There are several reasons that buyers may prefer to deal with the same seller even after product failure. For example, they may learn that a particular seller's product satisfies their needs. Alternatively, they may find it costly to go through the bidding and contracting process with other firms, or to spend the greater time required to deal with other firms. Money-refund and replacement remedies differ in their ability to induce the seller to make investments in producing low cost replacements, and in actually providing replacements. Because replacement policies achieve greater efficiency with respect to these activities, they are commonly observed.

As illustrated in the model below, the virtue of the replacement remedy, relative to a refund remedy, is its ability to stimulate a greater level of investment in some process or equipment that reduces the cost of providing replacement products. The investment could be transaction-specific, such as an investment in human or physical capital particularly suited to producing replacement products for a given buyer. Alternatively, the investment may be one of general value to the seller, such as the implementation of product service management or inventory control. To simplify the following discussion, only inventory investment will be considered.

With a money refund, the buyer may purchase another unit from the original seller provided that there are sufficient units in stock to satisfy the buyer's needs. On the other hand, if insufficient inventory is maintained, then the buyer must go elsewhere. Of course, the same is true for the replacement contract; if there are no products in stock, buyers will not get a timely replacement and may have to go elsewhere. However, with a replacement warranty, the buyer may demand damages for failure to replace, affecting the probability that the firm will invest in inventory. To see how this may occur, we will consider the following model.

Suppose there is one buyer who is interested in maximizing expected profit by purchasing one unit of product, good 1 , worth $V$ in the event that it works, and nothing if it fails. Denote the probability of failure by $f$. Suppose

\footnotetext{
Ideally, a different mix of warranty coverage and product price should be provided to these different types of consumers, resulting in both types being fully insured. It is well known to economists that, in general, efficient insurance cannot be achieved in this situation, because the seller cannot identify and separate the good risks from the bad.

In this setting, the replacement warranty provides a natural method of overcoming the adverse selection problem. There is never more than one type of consumer in the market, those with no product experience. The consumers suffering product failure receive a replacement, and if that replacement fails, they receive another replacement. The amount of insurance provided through the warranty is fixed before the consumers learn about their type, hence the adverse selection problem disappears. While not as forceful, this argument still applies when consumers have some information about their type before they make their first purchase. The adverse selection problem gets worse as consumers become better informed through experience with the product, and replacement warranties diminish this effect.
} 
further that there is a second type of product available, good 2, subject to the same probability of failure, $f$, but which is ill-suited to the buyer's needs and provides no value regardless of whether or not it works. ${ }^{61}$ The goods are experience goods, meaning that inspection of the product by the buyer will not reveal whether it is type 1 or 2; only through use can the suitability of the product be determined. ${ }^{62}$ Assume that the buyer finds a good match by obtaining good 1 , and a bad match by obtaining good 2. Before purchase the buyer knows that goods 1 and 2 are equally common.

The model is a four-period game populated by $N$ sellers ${ }^{63}$ who can furnish the good at a cost of $c$. If the product fails, the buyer may obtain a replacement from the original seller, or purchase one unit from any of the sellers. For expositional ease an extreme assumption is maintained, that the original seller can only produce a unit in the third period if an inventory investment of $I$ is made. This assumption captures a crucial element of the model, namely, the possibility for the original seller to make an investment that reduces the cost of providing a replacement. ${ }^{64}$

The sequence of actions in this model is depicted in Figure 1.

\section{FIGURE 1}

\section{Period 1}

All sellers make simultaneous offers of price and warranty terms. The buyer accepts one of the offers and purchases one unit.

\section{Period 2}

The successful seller in Period 1 decides whether to make an inventory investment.

\section{Period 3}

The buyer consumes the good. Both the buyer and the seller observe whether failure occurs. The buyer learns privately the quality of the product match. Given product failure the original seller decides whether to honor the remedy provision of the warranty policy. The buyer and seller may negotiate a settlement. They may also go to court in which case the seller loses and pays damages $D$.

\section{Period 4}

If the buyer got a replacement in Period 3 he or she consumes that product. Otherwise, the sellers make simultaneous price offers, and the buyer purchases a second unit.

In the first period of this game the sellers make a simultaneous choice of price and warranty remedies. A seller may offer a contract with no warranty, a free replacement, or a refund of the purchase price. The buyer selects one unit

61. This assumption is not crucial. The value of a bad match could be positive and less than $V$.

62. Assume that the seller cannot determine the quality of the match at any time.

63. Let $N$ represent an odd number, and assume that after making the initial purchase, the buyer faces $N-1$ sellers besides the initial firm, half of whom sell a good match, and half of whom sell a bad match. The same effect could be achieved by assuming that there is a continuum of sellers and that the production of each type of seller represents one-half of the density of the products manufactured by all sellers.

64. In this case, the seller can reduce the cost of replacement from $\infty$ to $c$ by investing $I$, where $c$ can be interpreted as the cost of finishing an unfinished good in inventory. 
from the firm offering the contract that maximizes the buyer's expected profit, and chooses randomly in the case of a tie. In the second period, the successful seller decides whether to invest a constant amount $I$ in inventory. In the third period, the buyer consumes the good purchased in the first period and discovers the suitability of the match, and whether the product works. Given product failure in the second period, the original seller decides in the third period whether to honor the warranty agreement, or breach and pay damages $D$. In the final period, if the product has failed or is a bad match, the buyer can re-enter the market in which sellers simultaneously set prices; however, no warranties are offered since the game ends in that period.

To predict equilibrium behavior in this model, the concept of a subgame perfect Nash equilibrium will be invoked, but the efficient outcome will be characterized before coming to this problem. The efficient outcome can be determined by solving the "social planner's" problem. The "social planner" is a hypothetical agent who receives all of the information received by the players, and compels them to take actions that maximize total surplus. This problem can be subdivided into questions concerning whether, and from whom, the buyer should purchase, and whether the inventory investment should be made.

First consider the question of optimal production in the third and fourth periods. If the state GW (good match and working product) occurs in period two, then no further production is required. If the state GF (good match and failure) occurs, then a second unit should be provided by the original seller, since the expected value of a good from the original seller is $(1-f) V$, compared to $1 / 2(1-f) V$, if the product is obtained from another seller. Of course, if the original seller has no inventory, then production must come from another seller. This repurchase would be worthwhile if $1 / 2(1-f) V \geq c$, which is assumed to hold. After the states BW (bad match and working product) or BF (bad match and failure) occur, then a unit should be obtained from a new seller.

Next, consider whether the investment of $I$ is optimal. Expending $I$ is only beneficial if the state GF arises, which occurs with probability $1 / 2 f$. Letting $\beta$ be the discount factor, the gain to making the investment is $1 / 2 \beta(1-f) V$, which is attributable to the certainty of getting a good match. Comparing the expected gain from investment to the cost yields the comparison $1 / 4 \beta f(1-$ f) $V \geq I$. If this inequality is rectified, then the investment is socially optimal.

Since all firms appear to be identical ex ante, the only question regarding first period production is whether a unit should be produced. It is easy to show that the condition assumed above, $1 / 2(1-f) V \geq c$, is sufficient to make first period production optimal. In the following characterization of subgame perfect Nash equilibrium, it will be assumed that this condition exists.

Now we turn to analysis of the game played by sellers. The efficiency conditions derived above will be used to determine whether market behavior is consistent with efficiency. 
The fourth period of the game is not reached if GW occurs or if GF occurs and a replacement is provided. If neither of these cases is realized, then sellers compete in prices for the sale of one unit. The sellers do not know what state has occurred, but the buyer does. Consider first the game in which $I$ is invested, so that the original seller can compete. The Nash equilibrium in prices has the buyer purchasing from the original seller at a price of

$$
P_{2}=c+1 / 2(1-f) V,
$$

if the state was GF, and purchasing from another seller at the price $P_{2}=c$, if $\mathrm{BW}$ or BF occurred. Notice that market power can be exercised by the original seller in the event that GF is the true state, since the buyer is sure of getting a good match. If $I$ is not invested, then $P_{2}+c$ and the buyer turns to a new seller in the fourth period.

The third period of the game involves the original seller's decision about whether to honor the remedy clause of a warranty agreement after GF or $B F .{ }^{65}$ If the inventory investment is not made, then a replacement promise cannot be honored and $D$ is paid by the seller to the buyer, while a moneyrefund agreement will be honored if and only if the first period price $P_{1} \leq D$.

If the investment is made, then a bargaining problem is created as the parties decide whether to honor the remedy clause of the warranty, to reach an out of court settlement, or to undertake litigation. We examine a very simple bargaining process in which the buyer decides whether to make a warranty claim, and then the seller chooses to honor the warranty or to make a settlement payment of $D$ to the buyer. In the case of a money-refund warranty, the seller offers the refund if $P_{1} \leq D$, and breaches otherwise.

In the case of a replacement warranty, assume that a replacement has no salvage value to a consumer experiencing state BF. Suppose the seller adopts a strategy of always providing replacements. The consumer experiencing BF will not make a claim on the seller since a replacement would be worthless to him. Clearly, a GF type consumer will take the replacement if offered, thus the expected cost of replacement is $1 / 2 c$. A strategy of always breaching results in both types of consumers making claims. The cost of breach is

$$
D-1 / 4(1-f) V \text {, }
$$

because the seller has a one-half probability of gaining profit $1 / 2(1-f) V$ from the GF type. Breach is chosen if and only if

$$
D<1 / 2 c+1 / 4(1-f) V .
$$

The case of a feasible exclusive replacement warranty can be interpreted as a subcase of this analysis in which $D=\infty$, leading to replacement for the GF consumer. ${ }^{66}$

65. Assume that the buyer cannot intentionally break the product and avoid detection so that no warranty claims occur after BW.

66. Note that this analysis of the bargain gives great bargaining power to the seller, who can now make a take-it-or-leave-it offer. The polar opposite bargain involving a take-it-or-leave-it offer by the buyer yields the following results: When $c \geq D$, the seller breaches; when $c+(1-f) V>D \geq C$ the 
In the second period, the seller, knowing generally what will happen in the subsequent periods but not knowing what state has been realized, decides whether to invest. If a money refund warranty has been negotiated, investment will be undertaken if $1 / 4 \beta f(1-f) V>I$. This same condition is applicable when no warranty has been negotiated. This condition, which is equivalent to the condition in the social planner's problem, arises because the seller's behavior in the third period is independent of the investment, and the profit accruing to the seller from making the investment is $1 / 2 \beta(1-f) V$, and is gained when the state is GF.

Alternatively, given a replacement warranty, the decision to invest depends on whether $D \geq 1 / 2 c+1 / 4(1-f) V$. If $D$ is large enough to satisfy this condition, then it was shown above that a replacement is always provided to a GF customer, and nothing is given to a BF customer. The gain from investment is avoidance of the damage payment $\beta D$, while the cost is $I+1 / 2 \beta c$, so the investment is made if $\beta f(D-1 / 2 c) \geq I$. Note that $D-$ $1 / 2 c \geq 1 / 4(1-f) V$, hence, for values of $I$ between $\beta f(D-1 / 2 c)$ and $1 / 4 \beta f(1-f) V$, investment will be made under the replacement warranty, even though it should not be made by an efficiency perspective. The extra incentive to make the inventory investment occurs because it allows the seller to avoid the large damage payment. In particular, if $D$ is very large, the effect is the same as if specific performance were implemented, and the seller disregards the possibility of state $\mathrm{BF}$, in order to avoid $D$.

Smaller values of $D$, such that $D<1 / 2 c+1 / 4(1-f) V$, result in breach by the seller in Period 3, even if the investment is made. Since the damage payment is made whether or not investment is undertaken, the gain from investment is $1 / 2 \beta(1-f) V$, the profit accruing from a sale to a good match, which occurs with probability $1 / 2 f$, and the cost is $I$. Thus, the condition for investment matches the efficient criterion.

All that remains to characterize the equilibrium of this model is to determine the first period price and warranty policy. Crucial properties of Nash equilibrium in prices and warranties are that an efficient warranty policy is chosen, and that the price is equal to average cost-a result akin to perfect competition. Provided $D$ is sufficiently small, either choice of remedy or no remedy at all would be efficient. $P_{1}$ is set low enough that expected profit is zero, offsetting the potential profits gained from a sale to a GF buyer in period four.

Importantly, this model demonstrates that the type of remedy, and the amount of damages assessed if the contracted remedy is not implemented, do not affect the level of inventory investment when bargaining is possible. In fact, when no remedy is provided, efficiency is still achieved, and the only impact of the remedy is on the distribution of profits. This is the obvious

seller makes a settlement payment of $c$ to the buyer; and when $D>c+(1-f) V$, the GF buyer gets a replacement and the BF consumer gets a settlement payment of $c$. 
Coasian result, but its validity is limited narrowly to this model which makes a certain special assumption.

In the discussion above, the model was designed so that the original seller could obtain the entire benefit from the bargain with the GF type buyer in period four; arguably, this assumption is invalid. For example, if buyers have downward sloping demand curves, or if the GF buyers have differing valuations for the product, and perfect price discrimination is impossible, then the seller will get less than the full benefit of the bargain. If the seller captures less than the full value of the inventory investment, then his or her incentive to make the investment is less than the incentive of the social planner. The implication is that for values of $I$ less than, but close to,

$$
1 / 4 \beta f(1-f) V \text {, }
$$

efficient investment will not be undertaken.

The only remedy that maintains an efficient level of investment when the seller does not capture the full value of the investment is a replacement remedy with $D=D^{*} \equiv 1 / 2 c+1 / 4(1-f) V$. To understand why, notice that $\beta f D^{*}$ corresponds to the expected $d$ social value of the inventory investment plus the expected cost of replacement. If the seller makes the inventory investment and provides the replacement when necessary, the expected cost is $I+1 / 2 \beta f c$. When faced with $D=D^{*}$, an investment is made if and only if $I \leq \beta f\left(D^{*}-1 / 2 c\right)$. This is identical to the condition for efficient inventory investment.

For $D<D^{*}$ the damage award is too small to deter a seller from breaching the promise to replace a defective product. The economic incentive to invest in inventory is the same as in the money-refund case. Either remedy may result in too little investment since the seller captures less than the full value of the replacement. For $D>D^{*}$, the replacement remedy produces too much investment, because the seller is overly concerned about avoiding the damage payment.

Up to this point the process determining $D$ has been unspecified. Efficiency results if $D^{*}$ is selected by the parties in a liquidated damage clause to be implemented if a replacement is not forthcoming. Alternatively, one might suspect that $D^{*}$ would be implemented at common law by dint of evolutionary pressures toward efficient common law damage rules.

To investigate the validity of this hypothesis, we will construct values of $D$ for two different damage rules applied to breach of warranty. If the court simply provides restitution, then $D=P_{1} / \beta$, where $P_{1}=c+1 / 2 f \beta c$. This value may be larger or smaller than $D^{*}$, and the implications for efficiency are unclear. To find the expectation damages, compare the profit to the GF type buyer when a replacement is provided, $1 / 2(1-f) V$, to the profits after breach, $1 / 2(1-f) V-c+D$, and do the same for the BF type buyer. This comparison yields $1 / 2(1-f) V-c$, and $1 / 2(1-f) V-c+D$, respectively. Assuming that the court can distinguish the states $W$ from $F$, but not the states $\mathrm{G}$ from $\mathrm{B}$, then the court will choose $D=D^{*}$ to equate the expected profit to the buyer who experienced failure and who was denied a replacement, to the 
expected profit of the buyer who received replacement. Thus, a very satisfying result has emerged: Expectation damages coupled with a replacement warranty assure an efficient level of investment.

\section{Replacement Warranties and Transaction-Specific Investment by the Buyer}

Besides providing an opportunity for discrimination and encouraging optimal investment by the seller, replacement warranties offer protection to the buyer against opportunistic behavior by the seller. The buyer becomes vulnerable to opportunism if he or she makes an idiosyncratic investment valuable only when consumed in tandem with a particular product. The possibility of product failure creates the peril.

Product-specific investments are undertaken to increase the value of a particular transaction. Reorganizing a production process to accommodate new equipment, training to use a particular firm's product, and purchasing inputs or complementary products that can only be used with a particular firm's product are all examples of transaction-specific investments by the buyer. Since these investments have little or no value outside of the relationship with a certain seller, the level of investment will be sensitive to the warranty remedy chosen.

In the case of a refund remedy, the buyer experiencing failure will be predisposed to repurchase from the original seller because the investment creates an implicit switching cost. When prices of all products are equal, the original seller is more attractive to the buyer because the investment makes that product more valuable. In this sense a switching cost arises.

A competing product could be enhanced through similar investment, but at the additional cost of redundant expenditure. The original seller can exploit this market power by offering a refund warranty and then raising the price to the repurchaser. The consequence is that foresighted, first-time buyers will reduce their transaction-specific investment because the potential gains from the investment are reduced by opportunistic behavior after product failure. Given a replacement warranty, the seller effectively commits to a price of zero after product failure, eliminating the possibility of exploiting the buyer's switching $\operatorname{cost}^{67}$ and guaranteeing the buyer the full benefit of the investment.

The argument that replacement warranties offer protection to buyers making idiosyncratic investments illustrates why the replacement remedy might predominate the refund remedy in the marketplace. But such a conclusion is premature. The refund remedy has the offsetting virtue of maintaining flexibility for the buyer who wants to change sellers after product

67. For a general discussion of the impact of switching costs in a market with differentiated products, see Klemperer, The Competitiveness of Markets with Switching Costs, 18 RAND J. Econ. 138 (1987). 
failure. Determining which remedy is superior requires a joint analysis of idiosyncratic investment and preference changes.

Whether the level of investment is more efficient under the replacement or refund warranty depends on the likelihood that the buyer will want to switch products as a result of a bad match with the original product. If all the products in a market are homogeneous, so that there would be no reason to switch, then the replacement warranty will be more efficient. It becomes less efficient relative to the refund warranty as products become more differentiated, and as buyers become less certain of the attributes of products.

These claims are substantiated in a model developed by the authors, ${ }^{68}$ illustrated in Figure 2, which consists of a Hotelling duopoly market with a single buyer located somewhere between the sellers who are found on the endpoints of the unit interval.

Figure 2

Hotelling MODEL

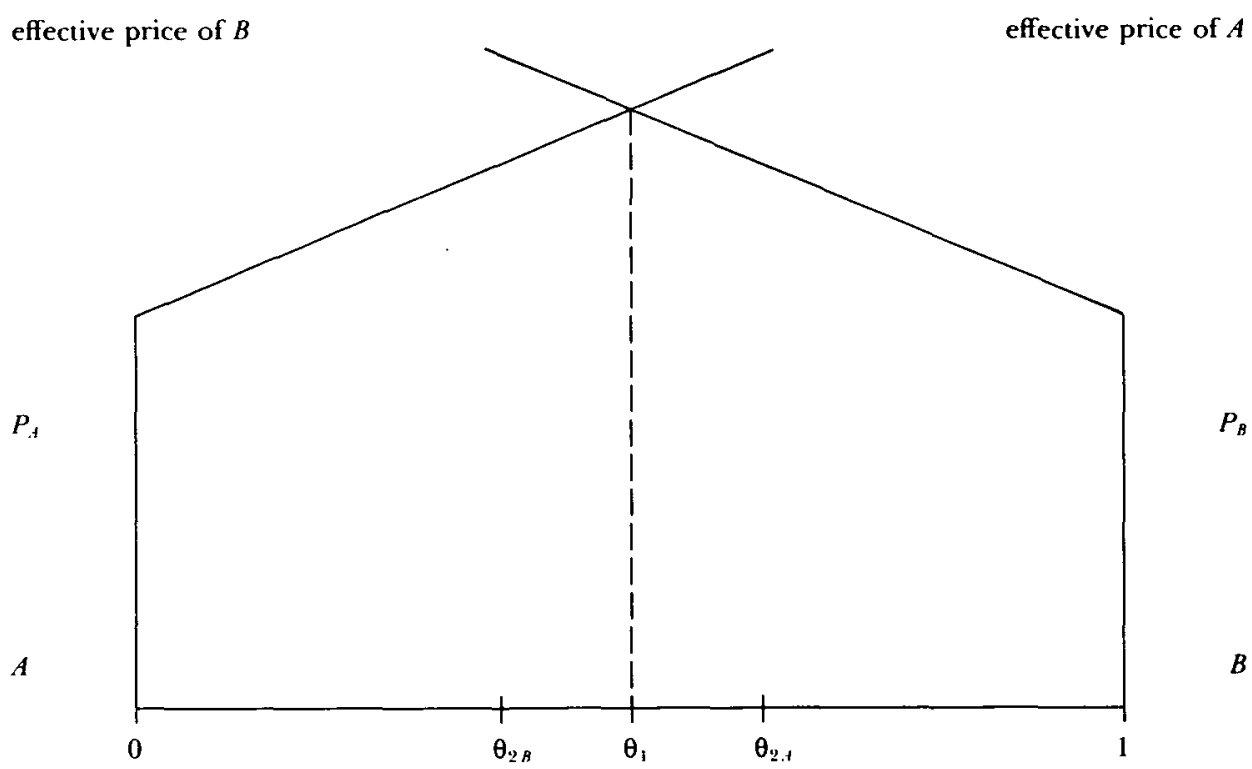

The buyer knows his or her preference for the products (represented by a position on the line), but the sellers are uncertain about the buyer's preference. The buyer chooses to purchase from the producer offering the lowest effective price, which is the sum of the actual price and the dissatisfaction cost. The dissatisfaction cost is incurred by the buyer from consuming a product that differs from the ideal product corresponding to the buyer's position on the line, and it increases as the distance between a seller and the buyer increase. The effective prices of the two products are shown in Figure 2. A buyer located to the left of $\theta_{1}$, where the effective cost lines

68. K. Chapman \& M. Meurer, Warranties, Switching Costs and Transaction Specific Investments by Consumers (1988) (unpublished manuscript). 
intersect, purchases from producer $A$, and one located to the right of $\theta_{1}$ purchases from $B$.

This structure is enriched to permit the study of warranty remedies by introducing a probability $f$ of product failure. After purchasing the product, but before it has been determined whether the product is functional, the buyer makes an investment that raises the value of the product. If the buyer gets a working product in the first period, he or she exits the market. Otherwise, the buyer re-enters the market in the second period. In addition, the buyer's preferences change between periods, ${ }^{69}$ possibly making a switch to the other product attractive.

In the case of a money refund, the subgame perfect Nash equilibrium is analyzed for the game having the following stages: (1) sellers simultaneously choose first period prices; (2) the buyer chooses one unit from either $A$ or $B$, and chooses a reliance investment; (3) the sellers simultaneously choose second period prices, if the product failed in the first period; and (4) the buyer chooses one unit from either $A$ or $B$.

Four variables must be chosen optimally to achieve efficiency in this environment: the level of investment, and $\theta_{1}, \theta_{2 A}$, and $\theta_{2 B}$, which are the market boundaries in the first period, the second period after a purchase of $A$ in the first period, and the second period after a purchase of $B$ in the first period, respectively. Because of the symmetry of the model $\theta_{1}^{*}=1 \% 2$, that is, the buyer purchases from the closest seller in the first period, minimizing dissatisfaction cost. The level of investment is chosen such that the expected marginal benefit equals marginal cost of investment. The optimal market boundaries in the second period are not at $1 / 2$, since the reliance investment creates a switching cost. Given a purchase of $A$ in the first period, $\theta_{2 A}$ is greater than $1 / 2$, and similarly, $\theta_{2 B}$ is less than $1 / 2$. The interpretation of this result is straightforward; given a reliance investment in $A$, even though the buyer's preference may have changed favorably toward $B$ so that the consumer is located at a point greater than $1 / 2, A$ might still be purchased because it is more valuable.

In the equilibrium in which both sellers use a money refund, the value of $\theta_{1}$ is $1 / 2$, but $\theta_{2 A}$ is too small relative to the optimal value, and $\theta_{2 B}$ is too large; furthermore, the reliance investment is always too low. The reliance investment is too low because the buyer is more vulnerable to the exercise of market power by the original seller as the value of the reliance investment rises. A consequence of the reduced investment is lower switching costs, moving the market boundaries in the second period closer to $1 / 2$.

If replacement warranties are used instead, $\theta_{1}$ is again equal to $1 / 2 . \theta_{2 A}$ and $\theta_{2 B}$ are no longer relevant because the buyer gets a replacement product. The reliance investment may be greater or smaller than the optimal investment, but will be closer to the optimum than the investment in the case

69. This change in preferences would most naturally result from new information received by the buyer regarding the nature of the products. 
of the refund warranty. The replacement remedy provides better incentives for reliance investment, because the buyer, rather than the seller, captures the benefit of the investment in the second period. The replacement remedy is less desirable because it eliminates the buyer's flexibility with respect to second period purchases.

The efficiency of the warranty policy can be improved if a broader conception of remedies is embraced. For example, the refund of the purchase price could be supplemented by recovery of the cost of investment through a liquidated damages clause, or as consequential damages. These measures could introduce overcorrection in the form of excessive investment, but that problem could be forestalled by contract terms specifying a permissible level of investment.

The possibility of implementing these more sophisticated remedies depends on what information is verifiable by the courts. A contract provision governing acceptable reliance investment might be difficult to construct and apply. A related problem is that the courts must be able to detect buyer misuse of the product designed to gain recovery for investments that are worth less than the damages.

In the previous section the replacement warranty coupled with expectation damages for breach motivated the seller to invest in inventory to avoid damage payments. In this section the replacement warranty protects the buyer who makes an investment raising the value of a particular seller's product from exploitation by the seller. The replacement warranty does not fare as well if the seller makes a product-specific investment that raises the value of the product to the buyer.

Given a replacement warranty, the seller has no incentive to make an investment that raises the value of the product to the customer, since the seller does not share in gains. With a refund remedy the seller can extract part or all of the value of the investment in the subsequent sale. The performance of the replacement warranty can be ameliorated by renegotiation. The contract could be modified to provide for product improvements in the replacement in return for additional payment from the buyer.

\section{$\mathrm{V}$ \\ Conclusion}

After noting the prevalence of repair-or-replacement terms as remedies in warranty policies, we examined the economics literature for an explanation of their predominance over money damage remedies. The comparative advantage theory is persuasive in justifying a preference for repair provisions, but not for replacement provisions. The literature does not explain satisfactorily why repair is coupled with replacement rather than refund in most warranties.

One explanation that deserves serious consideration is that the apparent exclusivity of the replacement remedy is illusory because the law does not 
make a commitment to replace a failed product credible, since a seller can breach that promise and pay damages. Further reflection on this possibility makes it clear that the market can make credible what the law does not. Firms do not routinely breach their promise to provide replacements because such action would tarnish their reputation and produce settlement or litigation costs.

This article advances three new theories on the economic role of warranties that generate different effects for replacement and refund warranties. The first holds that a claim of product failure can be used by the seller to sort customers into two classes, permitting discrimination between those classes. A replacement remedy is superior to a refund remedy for sorting purposes because it provides greater protection against arbitrage by the favored customers. The second theory focuses on investments by the seller that make the cost of replacement lower, such as investments in inventory or product service management. It shows that a refund remedy does not permit the seller to capture the entire benefit of these investments and leads to an inefficiently low level of investment. The replacement warranty, however, coupled with expectation damages if the replacement promise is breached, does achieve efficiency. Finally, this article develops a theory holding that warranties protect the transaction-specific investment of the buyer. The key observation in this model is that an investment by the buyer that raises the value of the original seller's product creates a cost with respect to switching to an alternative product upon failure of the original. If a refund is provided to a buyer after product failure, and the buyer wants to repurchase from the original seller, the switching cost allows the seller to appropriate much of the value of the buyer's investment, diminishing the incentive for the investment. The replacement remedy overcomes this problem by fixing the cost of repurchase at zero and eliminating the seller's market power. 
